\title{
ENGLISH VERSION:PHENOTYPIC PORTRAIT OF ESSENTIAL HYPERTENSION AS A TOOL TO INCREASE THE EFFICIENCY OF ITS DIAGNOSIS AND PROGRESSION IN MEN WITH POLYMORPHIC VARIANTS OF THE CARDIOTROPHIN-1 GENE
}

\author{
Matokhniuk M.O., Pashkova I.P., Zhebel V. M. \\ Vinnytsia National Pirogov Memorial Medical University
}

Chronic heart failure (CHF) is one of the prognostic complications of essential hypertension (EH), which is the most common non-communicable disease in the world. The aim of the study is to improve the effectiveness of diagnosis of EH progression based on cluster analysis, which is based on anthropometric, laboratory and systemic and intracardiac hemodynamics in men 40-60 years. The study included 50 men with asymptomatic EH aged $50.62 \pm 0.73$ years and 50 men with EH complicated by CHF aged $51.86 \pm 0.81$ years. All participants underwent standard cardio-graphic examinations, the plasma concentration of cardiotrophin-1 (CT-1) in the blood was determined by enzyme-linked immunosorbent assay (ELISA) and rs8046707 of the CT-1 gene in venous blood samples using the PLR method. The phenotypic portrait of the patient was distinguished by cluster analysis.

Key words: essential hypertension, chronic heart failure, cardiotrophin-1.

\section{Introduction}

High blood pressure (BP) is a leading risk factor for the global burden of disease, with a prevalence of $24 \%$ in men and $20 \%$ in women. In total, there are about 1.1 billion affected adults worldwide. It is estimated that hypertension leads to approximately 9.4 million deaths annually. In total, there are about 1.1 billion affected adults worldwide. [1]. Today, according to modern notions, essential hypertension $(\mathrm{EH})$ as a leading risk factor for cardiovascular disease is the result of a combination of genetic, environmental and social determinants [2]. It is known to cause structural and functional changes in the heart, among which the leading place is occupied by left ventricular hypertrophy $(\mathrm{LVH})$, which eventually leads to chronic heart failure (CHF), which further increases the mortality of such patients [3]. In particular, it is known that among patients with $\mathrm{CHF}$, the annual mortality ranges from $7 \%$ for stable / outpatients to $17 \%$ among inpatients, and the frequency of hospitalizations at 12 months is $44 \%$ and $32 \%$, respectively [4].

Despite the large number of studies of the etiopathogenesis of the above-mentioned pathological conditions, the factors that contribute to their occurrence and progression remain insufficiently studied. This problem is especially relevant in cases where there is no sufficient diagnosis of those phenomena that lead to deterioration of patients and unfavorable prognosis of $\mathrm{EH}$. Modern information technologies in combination with instrumental and biomarker surveys greatly facilitate the solution of forecasting issues. Cardiotrophin-1 (CT-1) is considered as one of the biomarkers that can be used for timely diagnosis and prediction of $\mathrm{LVH}$ in $\mathrm{EH}$, because changes in its plasma concentration are associated with both cardiomyocyte hypertrophy and the development of fibrotic processes in the heart muscle [5], and therefore reflect the process of formation of LVH. However, the expression of CT-1 is controlled by the coding gene, which must also be taken into account in the diagnostic process [6].

The above is the basis for using the methodology for managing several variables and their interaction to obtain appropriate diagnostic conclusions. One of the directions is the application of cluster analysis - a set of methods for determining subgroups of people with high heterogeneity. The groupings are built so that the degree of association is strong between members of the same cluster and weak between members of different clusters [7]. According to the literature, there is an assumption that the results of cluster analysis may help to identify the characteristics of the disease phenotype [8], and thus simplify the use in the treatment process of modern technologies of examination and use in determining the plasma level of CT-1.

The purpose of the study is to improve the effectiveness of diagnosis of progression of $\mathrm{EH}$ on the basis of cluster analysis, which is based on anthropometric, laboratory and indicators of hemodynamics in men aged 4060 years.

\section{Materials and methods}

We examined 50 men with asymptomatic $\mathrm{EH}$ with a mean age of $50.62 \pm 0.73$ years and 50 men with $\mathrm{EH}$ and complicated CHF IIA, stages II and III functional class, mean age $51.86 \pm 0.81$ years. All patients were observed from December 2017 to July 2018 and were hospitalized at Vinnytsia Regional Specialized Clinical Dispensary for Radiation Protection of the Ministry of Public Health of Ukraine and the Military Medical Clinical Center of the Central Region of the Air Force of Ukraine.

Criteria for exclusion from the study were the secondary nature of $\mathrm{EH}$, the presence of kidney and liver diseases, chronic obstructive pulmonary disease, tumors, endocrine diseases known to the subjects, diseases of the blood system and coronary heart disease, which arose before the diagnosis of $\mathrm{EH}$. The above diseases were ruled out through the collection of complaints, the results of objective and general clinical examination (including, if necessary, pre-diagnosis of coronary heart disease), as well as a detailed analysis of outpatient cards.

*To cite this English version: Maryna O. Matokhniuk, luliia P. Pashkova, Vadym M. Zhebel Phenotypic portrait of essential hypertension as a tool to increase the efficiency of its diagnosis and progression in men with polymorphic variants of the cardiotrophin-1 gene. // The Medical and ecological problems. - 2020. - Vol 24, № 5-6. - P. 14-16 
Determination of the cardiotrophin-1 gene polymorphism (rs8046707) was performed using the polymerase chain reaction method. Genotyping of the CT-1 gene was performed jointly with the Research Institute of Genetic and Immunological Foundations of Pathology and Pharmacogenetics of the Ukrainian Medical Stomatological Academy (Poltava). The concentration of CT-1 in blood plasma was determined using a set of reagents from RayBiotech, Inc. (USA) by enzyme-linked immunosorbent assay on a strip enzyme immunoassay analyzer "Humareader single" (Germany).

Structural and functional parameters of the myocardium were evaluated using ultrasound of the heart. According to the de Simone formula for people with complicated and asymptomatic $\mathrm{EH}$, the appropriate values of LV MMI were calculated - appropriate and inappropriate $\mathrm{LVH}$, which takes into account the following indicators gender, height, age and hemodynamic load of the left ventricle. ECG recording was performed according to the generally accepted method in 12 standard leads. Blood pressure measurements were performed according to the recommendations of WHO experts and ESC / ESH, ACC / AHA, ISH (2016-2020). Mathematical processing of the material was performed on a personal computer using the standard statistical package STATISTICA 10. To identify the phenotypes of patients used cluster analysis, namely the method of K-means.

\section{Results and discussion}

The etiology of $92 \%-95 \%$ of cases of essential hypertension is still not clearly defined. People with EH usually have a combination of several genetically determined abnormalities, but the phenotypes of these disorders can be adjusted by environmental factors, lifestyle and thus change the course of the disease. Therefore, important in the prognosis and promising for the patient is the impact on modifying risk factors and their prevention $[2,9,10]$. Using direct stepwise analysis for indicators that may affect the development of CHF on the background of EH in the matrix for discriminant analysis included interval indicators: age, BMI, concentration of CT-1 in blood plasma, LDL cholesterol, LA size, presence or absence of DD, inappropriate LVH, level of SBP and DBP.

The evaluation of the obtained results by analyzing the values of $\Lambda$-Wilkes (0.13), X2 (311), as well as Canonical $R(0.95)$ - allows us to consider the presented model useful. The next step of the study was to conduct a cluster analysis of these indicators. Then the selected indicators were translated into an interval scale: age 140-50 years, 2-51-60 years; body weight using the formula for calculating BMI - 1-normal, 2-overweight, 3obesity; LDL cholesterol in accordance with the recommendations for the diagnosis and treatment of dyslipidemia 1- $<2.6 \mathrm{mmol} / \mathrm{I}, 2->2.6 \mathrm{mmol} / \mathrm{I}$, LVH- 1- appropriate LVH, 2 - inappropriate LVH; LA: $1-<4.0$ cm., 2 -> 4.0 $\mathrm{cm}$.; DD: 1 - normal, 2- diastolic dysfunction of the I degree, 3- II degree, 4-III degree, blood pressure - 1-130139 / 85-89 mm Hg, 2-140-159 / 90- 99 mm Hg, 3- 160179 / 100-109 mm Hg, 4- $\geq 180$ / $\geq 110$ mm Hg. Using ROC-analysis calculated the threshold level of CT-1 in blood plasma - $303.81 \mathrm{pg} / \mathrm{ml}$ (sensitivity-87.5\%, specificity-92\%), so respectively $1-<303.81 \mathrm{pg} / \mathrm{ml}, 2->303.81$ $\mathrm{pg} / \mathrm{ml}$. Then the indicators were standardized for further analysis. Two clusters selected. It was found that 1 cluster included 42 people with asymptomatic $\mathrm{EH}$, and the cluster of 2- 8 people with asymptomatic $\mathrm{EH}$, and 50 people with complicated $\mathrm{EH}$. With the help of a cluster portrait (Fig. 1) it is determined that cluster 2 has not only higher anthropometric and laboratory indicators of hemodynamics, which are associated with a more severe course of $\mathrm{EH}$ but also a higher concentration of CT-1 in blood plasma. Thus, individuals who can be assumed to be the second variant of the phenotype may have a worse prognosis.

However, the question arises as to the importance of determining both the plasma concentration of CT- 1 and the genotype variant of the coding gene.

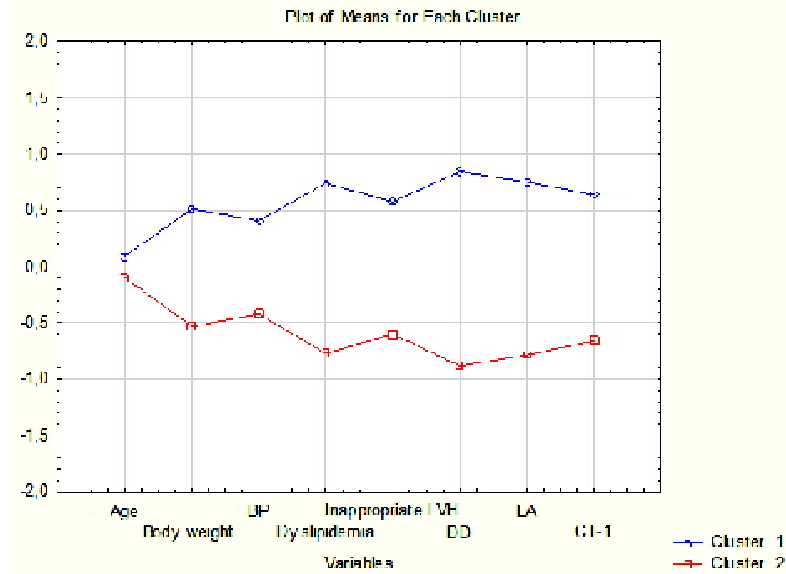

Fig. 1 Cluster portrait - the values of parameters within the distributed clusters

The next step of the study was to study the frequency distribution of genotypes of the CT-1 gene in these clusters (Table 1). The frequency distribution of genotypes of the CT-1 gene in men with EH, residents of the Podolsk region of Ukraine, corresponded to the Hardy-Weinberg equilibrium. Due to the low incidence of genotype $A A$, individuals with carriers of genotypes bearing the $A$ allele ( $G A$ and $A A$ ), it was decided to combine into one group carriers of genotypes GA + AA. Thus, among patients included in cluster 2 , individuals with the GG + AA genotype of the CT-1 gene predominate.

Table. 1

Frequency of genotype distribution of CT-1 gene in clusters, \%

\begin{tabular}{|c|c|c|c|}
\hline & GG genotype & $\begin{array}{c}\text { GA + AA } \\
\text { genotypes }\end{array}$ & $p$ \\
\hline $\begin{array}{c}\text { Cluster 1 } \\
(n=42)\end{array}$ & $\begin{array}{c}47.62 \\
(n=20)\end{array}$ & $\begin{array}{c}52.38 \\
(n=22)\end{array}$ & $p>0.05$ \\
\hline $\begin{array}{c}\text { Cluster 2 } \\
(n=58)\end{array}$ & $\begin{array}{c}25.86 \\
(n=15)\end{array}$ & $\begin{array}{c}74.14 \\
(n=43)\end{array}$ & $p<0.05$ \\
\hline
\end{tabular}

To reflect the results of the study more accurately, as well as their applied individualization for a particular man with $\mathrm{EH}$, we applied linear discriminant Fisher's analysis with the creation of a mathematical model of disease prognosis for persons classified in the 1st and 2nd cluster in the form of a scheme of classification equations. The model of the prognosis of the disease in men with asymptomatic and complicated $\mathrm{EH}$, aged $40-60$ years, residents of the Podilsk region of Ukraine who are included in the 1st and 2nd cluster is as follows:

(1) Cluster $1=-251.38+14.26$ * Age $+3.63 * \mathrm{DD}+$ $110.94 *$ LDL cholesterol $-0.036^{*} \mathrm{CT}-1+9.91 * \mathrm{LA}+7.20$ * $\mathrm{BP}+4.76$ * body weight +3.31 * inapp. LVH.

(2) Cluster $2=-311.65+15.66^{*}$ Age +12.28 *DD + $118.53 *$ LDL cholesterol $-0.014^{*} \mathrm{CT}-1+12.17{ }^{*} \mathrm{LA}+$ 7.95 * BP+ 7.39 * body weight $+4.21^{*}$ inapp. LVH.

The model is valid for the value (Willks 'Lambda $=$ $0.21 ; F=(7.92) 50.24 ; p=0.0001)$. The overall accuracy 
of the method was $97.9 \%$, the sensitivity of the method is - $95.55 \%$, specificity - $90.29 \%$. The patient's prognosis will belong to the cluster for which the classification equation will be higher than the other. If the obtained numerical value is greater in formula (1) - this indicates that the patient with a probability of $90.29 \%$ has a better prognosis of $\mathrm{EH}$ of varying severity, and if the numerical value is greater in formula (2) - examined with probability $95.55 \%$ have a risk of developing $\mathrm{CHF}$ due to $\mathrm{EH}$.

Cluster analysis, namely k-means, is quite common in various fields of medicine and beyond. Anthropologists $\mathrm{J}$. Chekanovsky began using this analysis in 1911, and Driver and Kroeber in 1932. In 1944, the method began to be widely used to classify the theory of signs in the psychology of personality [11]. According to the literature, cluster analysis was performed in patients with $\mathrm{EH}$, namely in the Chinese population to identify the main factors in the development of coronary heart disease and $\mathrm{EH}$ in Europe to determine the factors influencing such complications of $\mathrm{EH}$ as stroke [8,12]. Lozynska M.S. used this analysis to identify the phenotypic portrait in men with EH carriers of polymorphic variants of the aldosterone synthase gene [Lozinskaya MS]. The data obtained in our study suggest that men who entered cluster 2 have a more unfavorable prognosis of $\mathrm{EH}$. Among them, carriers of GA + AA genotypes are significantly more common ( $p<0.05$ ). For practical use, discriminant equations are calculated for each cluster, which include not only well-known anthropometric, laboratory and ultrasound indicators, but also a new biomarker KT-1.

\section{Conclusions}

1. By means of the cluster analysis the phenotypic portrait of the patient (cluster) in which to known indicators is allocated (age, body weight, blood pressure, inapp. LVH, LDL cholesterol, LA, DD) growth which is characterized by a worse prognosis of $\mathrm{EH}$ is added to a higher concentration of CT-1 in blood plasma.

2. Among men who have a more unfavorable course of $\mathrm{EH}$, carriers of $\mathrm{GA}+\mathrm{AA}$ genotypes are more common $(p<0.05)$, which may indicate an unfavorable prognosis in carriers of these variants of the genotype of the CT-1 gene.

3. Using discriminant Fisher analysis, a mathematical model was created to individualize the prognosis of $\mathrm{EH}$ in men.

\section{References}

1. Sánez Tähtisalo $\mathrm{H}$, Ruotsalainen $\mathrm{S}$, Mars $\mathrm{N}$, et al. Human essential hypertension: no significant association of polygenic risk scores with antihypertensive drug responses. Sci Rep 2020; 10:11940 https://doi.org/10.1038/s41598$\underline{\text { 020-68878-3 }}$
2. Carey RM, Muntner P, Bosworth HB, Whelton PK. Prevention and Control of Hypertension: JACC Health Promotion Series. J Am Coll Cardiol. 2018;72(11):1278-1293. doi:10.1016/j.jacc.2018.07.008

3. Goropko OY. Obesity and hypertension: modern views on the pathogenesis, diagnosis and treatment. Family Medicine 2019; 2 (82): 18-24

4. Skibchik VA, Chronic heart failure: new approaches to diagnosis and treatment. Medicines of Ukraine 2016; 10 (206): $\quad 34-41 \quad$ https://doi.org/10.37987/19979894.2016.10(206).207666

5. Pemberton CJ, Raudsepp SD, Yandle TG, et al. Plasma cardiotrophin-1 is elevated in human hypertension and stimulated by ventricular stretch. Cardiovasc Res 2005;68:109-17.

6. Pennica D, Swanson TA, Shaw KJ, Kuang W J, et al. Human cardiotrophin-1: protein and gene structure, biological and binding activities, and chromosomal localiza$\begin{array}{lll}\text { tion. } & \text { Cytokine. 1986; } 183-189 .\end{array}$ https://doi.org/10.1006/cyto.1996.0026

7. Weatherall M, Shirtcliffe P, Travers J, Beasley R. Use of cluster analysis to define COPD phenotypes. European Respiratory Journal 2010; 36 (3):472-474; doi: 10.1183/09031936.00035210

8. Guo Q, Lu X, Gao Y. et al. Cluster analysis: a new approach for identification of underlying risk factors for coronary artery disease in essential hypertensive patients. Sci Rep 2017; 7: 43965. https://doi.org/10.1038/srep43965

9. Curfman G, Bauchner H, Greenland P. Treatment and Control of Hypertension in 2020: The Need for Substantial Improvement. JAMA. 2020; 324(12):1166-1167. doi:10.1001/jama.2020.13322

10. Pashkova Yu.P. Polymorphism of the brain natriuretic peptide gene and plasma concentrations of $\mathrm{M}$ - and $\mathrm{C}$ - natriuretic peptides in men with hypertension complicated by chronic heart failure. Clinical significance: author's ref. dis. of cand. of med. sciences. State Institution "National Research Center" Institute of Cardiology named after Academician MD Strazheska "of the National Academy of Medical Sciences of Ukraine, Kyiv, 2017.

11. Blashfield RK, Aldenderfer MS. The Methods and Problems of Cluster Analysis. In: Nesselroade J.R., Cattell R.B. (eds) Handbook of Multivariate Experimental Psychology. Perspectives on Individual Differences. Springer, Boston, MA. 1988 https://doi.org/10.1007/978-1-4613-0893-5 14

12. Aszalós Z, Barsi P, Vitrai J. et al. Hypertension and clusters of risk factors in different stroke subtypes (an analysis of Hungarian patients via Budapest Stroke Data Bank). J Hum Hypertens. 2002; 16:495-500 https://doi.org/10.1038/sj.jhh.1001428

13. Lozynska MS. Hereditary preconditions for myocardial remodeling in men with hypertension, residents of the Podolsk region. Diagnostic and clinical significance. Clinical significance: author's ref. dis. ... doctor of philosophy. Vinnytsia National Medical University. MI Pirogov Ministry of Health of Ukraine, Vinnytsia, 2020.

Матеріал надійшов до редакції 00.10.2020 